\title{
PERFORMANCE COMPARISON OF AN ALTERNATIVE CONVERTER FOR WIND POWERED SWITCHED RELUTANCE GENERATORS
}

\author{
OLIVEIRA, E. S. L., FLEURY, A., FLEURY-NETO, G. A. C., OLIVEIRA, T. F. \\ Laboratório de Máquinas Elétricas, Departamento de Engenharia, Universidade Católica de Goiás, Pça. Universitária, 1440, \\ Goiânia - Goiás, Brasil \\ E-mails: edu_sylvestre@hotmail.com, afleury@terra.com.br, gefleury@gmail.com, thiagofernandes@msn.com
}

\begin{abstract}
The subject of this paper is a comparison of the performances of two converter topologies for Switched Reluctance Generators - SRG. It deals with this special electrical generator excited through a rectified DC link. The prime mover is a wind turbine. Mathematical model and simulation results are presented. Both the power converters topologies implemented work well but the alternative one is cheaper and more efficient than the conventional half-bridge one. Furthermore, only the alternative converter allows to feed the load from the grid even when the SRG is not running. This is good for complementary wind power. Experimental results are presented. It was shown that the SRG worked as expected and that the alternative topology reached expectations.
\end{abstract}

Keywords - alternative converter topology, special electrical generator, mathematical model, wind power.

\section{NOMENCLATURE}

$\begin{array}{ll}U & \text { Applied voltage. } \\ i & \text { Phase current. } \\ R & \text { Phase resistance. } \\ L & \text { Phase inductance. } \\ \mathrm{E} & \text { Back electromotive force. } \\ \omega & \text { Rotor angular speed. } \\ C_{m} & \text { Applied mechanical torque. } \\ C_{e m a g} & \text { Electromagnetic torque. } \\ J & \text { Moment of inertia. } \\ D & \text { Coefficient of friction. } \\ \theta & \text { Rotor angular position. } \\ t & \text { Time }\end{array}$

\section{INTRODUCTION}

The world focus is now the environmental protection. Energy savings are a main strategy to get good results in the efforts to preserve the planet. Therefore, the engineering is required to develop and use new technologies.

Wind power is a recent renewable primary energy source that must be considered in the future global energy matrix. In fact wind power plants are growing in acceptance and competition. Wind power requires some special electric generator to work under continuously variable speed. In this context, the Switched Reluctance Generator - SRG is investigated as an alternative to maximize wind power efficiency. This machine is robust, easy and cheap to construct and to maintain. In many aspects this kind of machine, now available, works better than others like the induction machine.

The absence of permanent magnets in the stator and windings in the rotor; low manufacturing costs; low maintenance; robustness; reliability; high efficiency; increased power density [1] are some advantages of the SRG side by side with a large range of operational speed and a predicted low wholesale price.

Despite they are somewhat noisy and its control is essentially non-linear the SRG was largely benefited with the recent advances on power electronics and micro processing. Torque, current and voltage ripples are inherent to the SRG, but the modern power electronic minimized these disadvantages.

The application of this machine is now rising. The More Electric Aircrafts - MEA projects, shaft aligned starter alternators, wind power and hybrid vehicles are some quoted applications [2].

The best converter for this machine is to be defined. This paper presents a comparison between two converters that can be used in a wind powered SRG. The tests results shows that the conventional half bridge converter, largely used, is not a good choice. A reduced switches count converter emerges with some remarkable advantages that are shown. Mathematical model.

The switched reluctance machine - SRM is an unsuccessful old idea now renewed by the recent power electronics and microprocessors developments. It is a doubly salient poles arrangement as showed in Fig. 1. It works as a motor or as a generator depending on the firing angles [3].

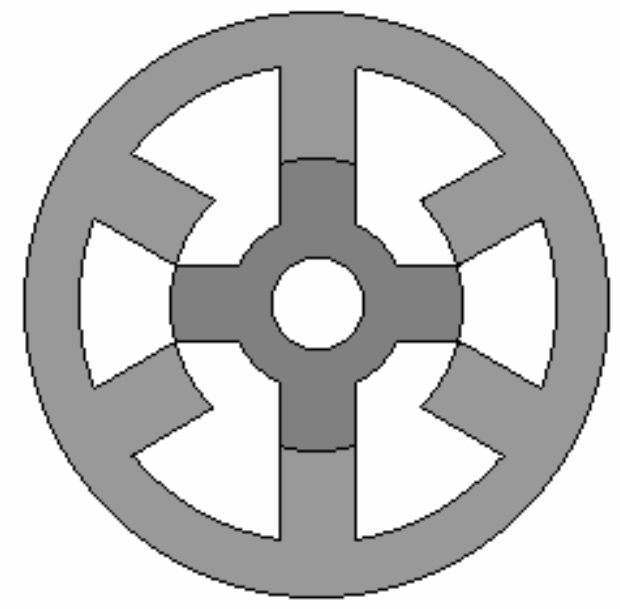

Fig. 1 A 6 x 4 doubly salient SRM.

The inductance of an excited winding reaches its maximum when a pole of the rotor is aligned with the stator 
pole corresponding to this winding.. This is a position of stable equilibrium and the natural trend is the alignment of these poles in the SRM. When the rotor is moved from the aligned position by a mechanical agent, the resulting torque produces a back electromotive force (EMF) in addition to the applied voltage and then the machine generates electrical power acting as a SRG.

In a SRG, the mechanical power received, in this case the strength of the winds, collected by turbine blades, promotes the slip between the stator and the rotor poles generating electrical power

The voltage equation for a phase of the $\mathrm{SRG}$ is:

$$
U=R i+L \frac{d i}{d t}+E
$$

where the back EMF is given by equation (2),

$$
\begin{gathered}
\mathrm{E}=i \omega \frac{\partial L}{\partial \theta} \\
\omega=\frac{\partial \theta}{\partial t}
\end{gathered}
$$

and

The windings are excited by a DC link. Since $i$ and $\omega$ must be positive, the signal of $E$ is determined by $\partial L / \partial \theta$. From equation (2) it can be seen that when $\partial L / \partial \theta<0$ the back EMF is negative, thus there is a conversion of mechanical power into electrical power [3].

The dynamic torque equation is:

$$
C_{m}+C_{\text {emag }}-J \frac{d \omega}{d t}-D . \omega=0
$$

As there are three different phases each one with its own instantaneous inductance, voltage and current, the electromagnetic torque is given by (5).

$$
C_{\text {emag }}=\frac{1}{2}\left(i_{r}^{2} \frac{\partial L_{r}}{\partial \theta}+i_{s}^{2} \frac{\partial L_{s}}{\partial \theta}+i_{t}^{2} \frac{\partial L_{t}}{\partial \theta}\right)
$$

Considering all the relations above the mathematical model for a phase of the SRG is as in (6).

$$
\begin{aligned}
& {\left[\begin{array}{c}
\dot{i}_{r} \\
\dot{i_{s}} \\
\dot{i}_{t} \\
\dot{\omega} \\
\dot{\theta}
\end{array}\right]=\left[\begin{array}{ccccc}
L_{r} & 0 & 0 & 0 & i_{r} 2 r_{r} \\
0 & L_{s} & 0 & 0 & i_{s} 2 r_{s} \\
0 & 0 & L_{t} & 0 & i_{t} 2 r_{t} \\
0 & 0 & 0 & J & 0 \\
0 & 0 & 0 & 0 & 1
\end{array}\right]^{-1}\left[\begin{array}{c}
v_{r} \\
v_{s} \\
v_{t} \\
C_{m} \\
0
\end{array}\right]-\left[\begin{array}{ccccc}
L_{r} & 0 & 0 & 0 & i_{r} 2 r_{r} \\
0 & L_{s} & 0 & 0 & i_{s} 2 r_{s} \\
0 & 0 & L_{t} & 0 & i_{t} 2 r_{t} \\
0 & 0 & 0 & J & 0 \\
0 & 0 & 0 & 0 & 1
\end{array}\right]^{-1} \times} \\
& \times\left[\begin{array}{ccccc}
R_{r} & 0 & 0 & 0 & 0 \\
0 & R_{s} & 0 & 0 & 0 \\
0 & 0 & R_{t} & 0 & 0 \\
-i_{s} r_{s} & -i_{s} r_{s} & -i_{t} r_{t} & D & 0 \\
0 & 0 & 0 & -1 & 0
\end{array}\right]\left[\begin{array}{c}
i_{r} \\
i_{s} \\
i_{t} \\
\omega \\
\theta
\end{array}\right]
\end{aligned}
$$

Where: $r_{r}=\frac{1}{2} \frac{\partial L_{r}}{\partial \theta} ; r_{s}=\frac{1}{2} \frac{\partial L_{s}}{\partial \theta}$ and $r_{t}=\frac{1}{2} \frac{\partial L_{t}}{\partial \theta}$
The matrix of states in equation (6) completely describes the dynamic behavior of the SRG.

\section{SIMULATIONS}

Fig. 2 shows the block diagram of wind powered SGR. All the power delivered to the load passes through the machine windings and its converter [2]. Two topologies of converters are used to simulate the machine operation.

One of them is the conventional half bridge converter and the other is a topology excluding a controlled switch per phase. The last one is a reduced switches count converter that increases the participation of the DC excitation source in the load supply. This cheaper topology allows the grid to feed the load through the SRG even when there is not mechanical energy and so the SRG is stopped. - a remarkable advantage.

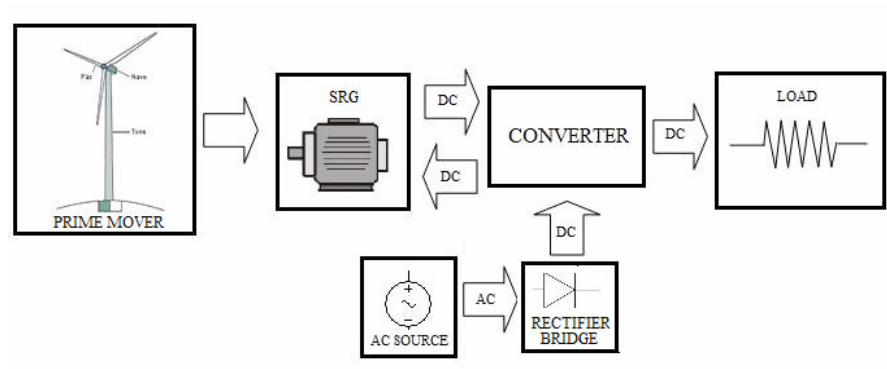

Fig. 2 - Block diagram of the SRG.

Fig. 3 shows the electrical scheme for a phase of the half bridge converter and Fig. 4 does the same for the alternative reduced switches count converter topology.

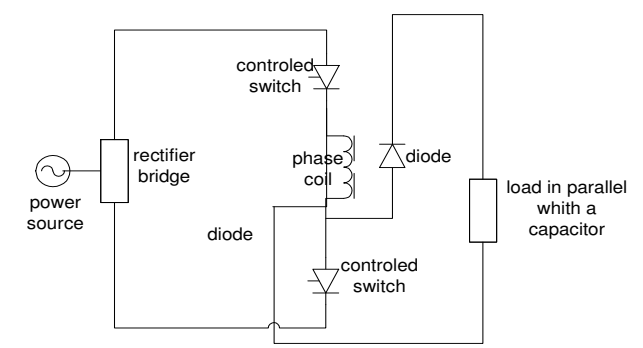

Fig. 3 - Electrical scheme of a phase of the half-bridge converter.

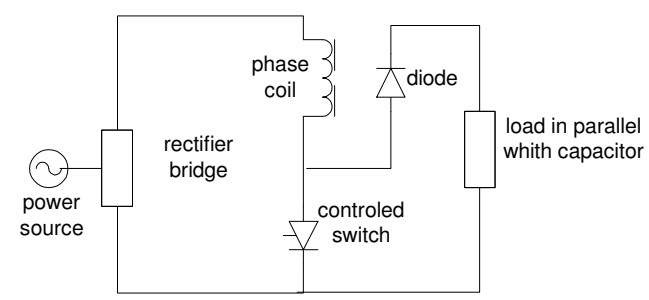

Fig. 4 - Electrical scheme of a phase of the cheaper alternative converter.

In both topologies all electrical power came from the AC source through the rectifier bridge and from the SRG goes to the load passing through the SRG windings and the converter.

Using the half bridge converter topology to drive the SRG the excitation period of each phase begins when the controlled switches are conducting, the inductance is increasing, the diodes are not conducting and the phase 
winding generates a positive counter EMF. The generating period begins when the controlled switches are not conducting, the inductance is decreasing, the diode is conducting and the phase winding generates a negative counter EMF. In this case the voltage over the load is that of equation (2). Using the reduced switches count converter topology the remarkable change is that the voltage over the load is E plus the output voltage of the rectifier bridge.

Fig 5 show the active circuit during the excitation period of the alternative reduced switches count converter topology. Fig. 6 show the active circuit during the generating period for the same topology. It can be observed in Fig. 6 that de applied voltage is in series with de back electromotive force.

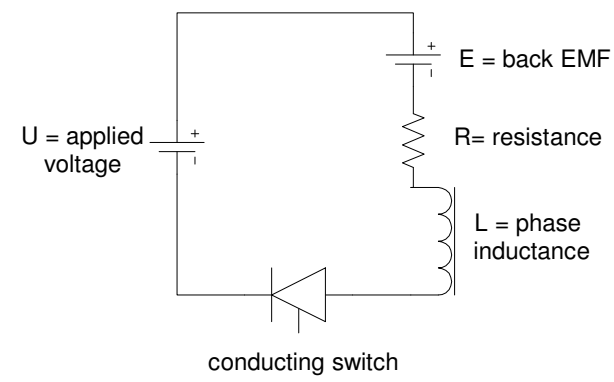

Fig. 5 - Active circuit during the excitation period using the alternative converter

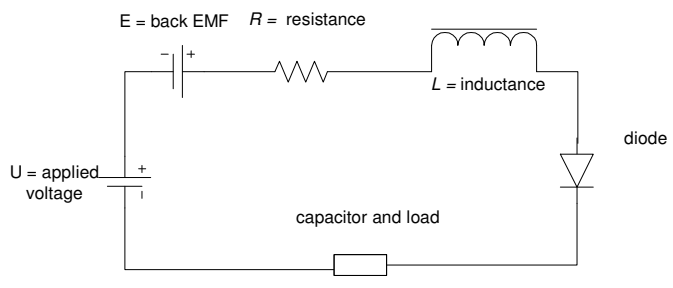

Fig. 6 - Active circuit during the generating period using the alternative converter.

The SRG mathematical model is evaluated for both converters using a computing program whose inputs are the phase voltages and the mechanical torque. The outputs are the currents at the phases, the angular speed and the rotor position. Each new set of values for the phase voltages and for the torque is used to feedback the program to evaluate the next state. The matrix of states, equation (6) is solved considering the saturation effects. The computing program uses dynamic values resulting from the relations among the different circuit elements of the converter and from the relations among them and the AC source, the rectifier, the SRG and the load. It is necessary only the instantaneous rotor position to control the gate signals. Optical sensors give this data. Such modeling strategy for simulations allows an evaluation of the converters behavior under different conditions like speed or excitation voltage and others. As the alternative converter allows power passes through the windings when the rotor of the SRG is not running, this converter can be used in grid connection without power interruptions. The SRG is a DC machine and when power came from different sources flow in DC mode through a converter, as showed in Fig. 6, problems of synchronism are avoided. Furthermore, to supply AC loads it is possible to model the output signal using an PWM inverter.

The simulations were done using data from a prototype of SRG wich parameters and dimensions are given in Table I.

TABLE I CHARACTERISTICS OF SRG USED

\begin{tabular}{|l|l|}
\hline Parameter & Value \\
\hline Air Gap Length & $0.4 \mathrm{~mm}$ \\
\hline Coefficient of Friction & 0.026 N.m.s \\
\hline Conducting Angle & 30 degrees \\
\hline Inductance (Aligned Position) & $36 \mathrm{mH}$ \\
\hline Inductance (Unaligned Position) & $3 \mathrm{mH}$ \\
\hline Inertia & $0.0028 \mathrm{~kg} . \mathrm{m}^{2}$ \\
\hline Number of turns per phase & $50 \mathrm{turns} / \mathrm{phase}$ \\
\hline Rotor Diameter & $70 \mathrm{~mm}$ \\
\hline Rotor Slot & $11.7 \mathrm{~mm}$ \\
\hline Rotor Teeth Width & $20 \mathrm{~mm}$ \\
\hline Rotor Yoke & $12.4 \mathrm{~mm}$ \\
\hline Shaft Diameter & $22 \mathrm{~mm}$ \\
\hline Stack Length & $107 \mathrm{~mm}$ \\
\hline Stator Diameter & $140 \mathrm{~mm}$ \\
\hline Stator Slot & $22.5 \mathrm{~mm}$ \\
\hline Stator Teeth Width & $19 \mathrm{~mm}$ \\
\hline Stator Yoke & $12 \mathrm{~mm}$ \\
\hline
\end{tabular}

Each phase winding has 50 turns of copper wire AWG 15, to support a current of 10A. The driving strategy states that each phase is fired during 30 degrees and just one phase is fired at a time.

In this simulation, the conduction angle of a phase switch begins 4.7 degrees before the peak of the inductance of that phase. The excitation period 25.3 degrees after the peak. From this point the phase transfers power to the capacitor and to the load until the rotor reaches the minimum inductance position at around 45 degrees. Fig. 7 shows the sequence for the phases.

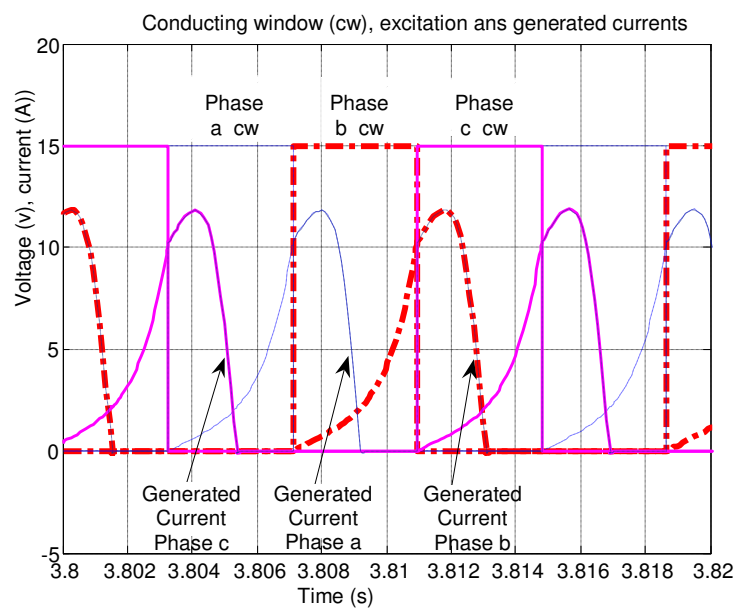

Fig. 7 - Current, inductance and conduction angles of a phase. 
The voltage that excites a phase winding is the rectified voltage that supplies the converter, as shown in Fig. 8. During the excitation process the phase switch is conducting and its diode is not conducting as it is inversely biased. When the power switch is turned off, the diode becomes directly biased and starts conducting. As a result, the voltage at the winding terminals is a negative back electromotive force which, added to the rectifier voltage, supplies the capacitor and the load.

Fig. 9 shows the variables involved in the electromagnetic torque produced in the same phase.

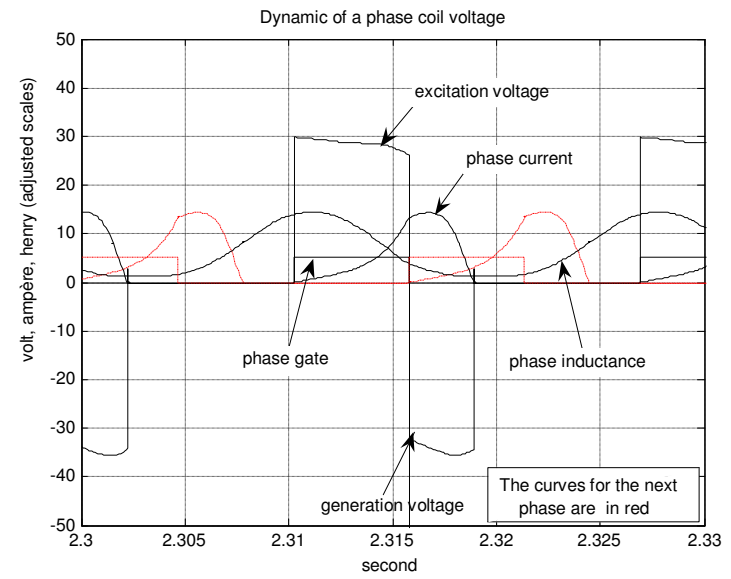

Fig. 8 - Dynamics of power generation.

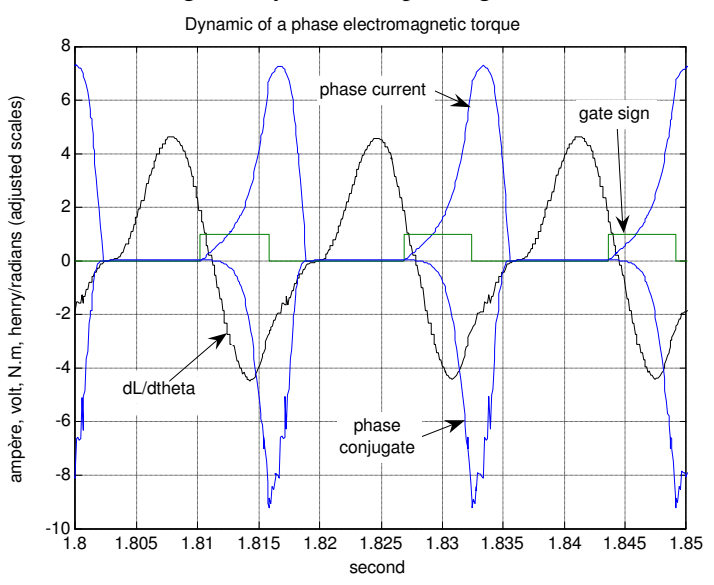

Fig. 9 - Electromagnetic torque at a phase.

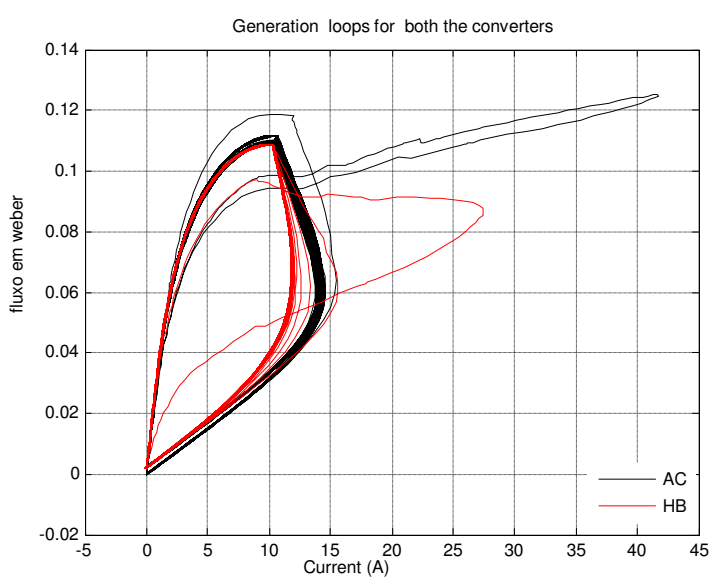

Fig. 10 - Sample of generation loops obtained from simulations under the same conditions.
When a half-bridge converter is used in simulations, the losses increase and, consequently, less power is supplied to the load. To illustrate this, Figure 10 shows a sample of generation loops obtained from simulations under the same conditions using the half-bridge converter and the reduced switches count converter. One can see that the area of the reduced count converter is greater than the other. These areas are proportional to the generated energy and so the SRG generates more energy when driven by the reduced count switched converter. Furthermore, using the half-bridge converter it is not possible to supply the load when the SRG is not running.

\section{EXPERIMENTAL RESULTS}

Results of two tests carried out with the prototype of SRG (Fig. 11) are showed below.

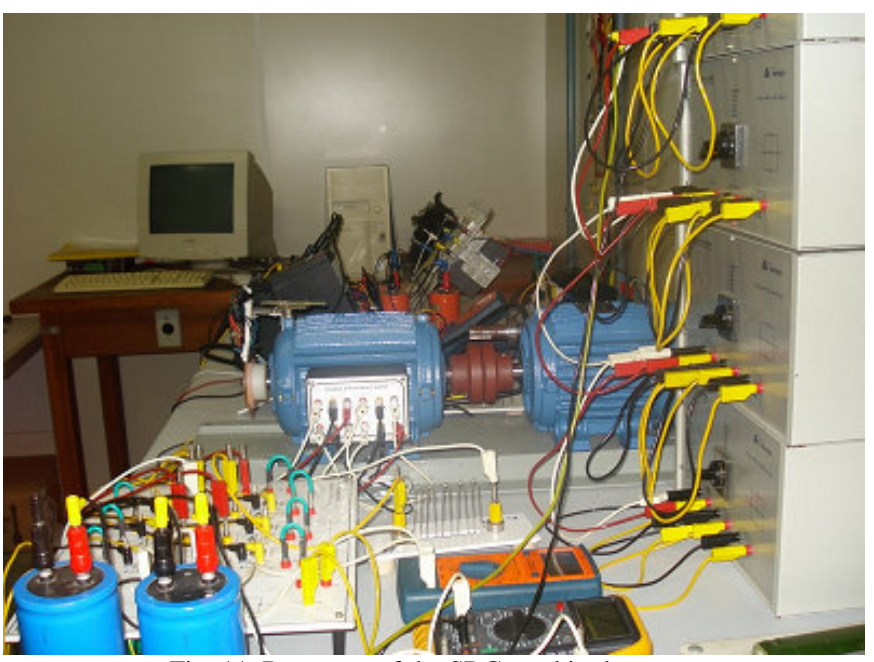

Fig. 11. Prototype of the SRG used in the tests.

The converter was assembled with Power MOSFET's and diodes. The load used in these tests was a resistance of $10.8 \Omega$. A $10 \mu \mathrm{F}$ capacitor was used in the output to stabilize the load voltage.

In the first test the alternative converter was used and the SRG was running at the speed of 1280rpm. The voltage of the AC input source could be adjusted to get the desired output power to the load. The measurements were $35 \mathrm{~V}$ and $10 \mathrm{~A}$. So, the DC excitation power was $350 \mathrm{~W}$.

Fig. 12 shows the current and voltage over a phase winding. It can be seen that the back EMF is negative providing power to the load even when the excitation period ends.

The output obtained as a consequence of the input and the process of generation is shown in Figure 13. The measurements were $72 \mathrm{~V}$ and $7 \mathrm{~A}$. So, the output power was $504 \mathrm{~W}$. As the excitation power was $350 \mathrm{~W}$, the generated power was $154 \mathrm{~W}$ delivered to the load plus all the losses of the process. 


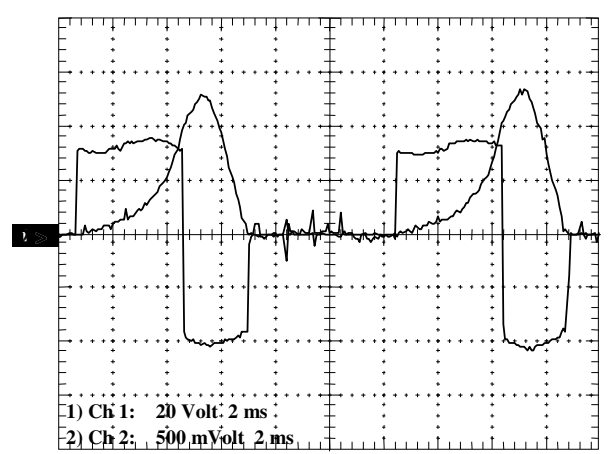

Fig. 12 - Voltage and current over a phase winding.

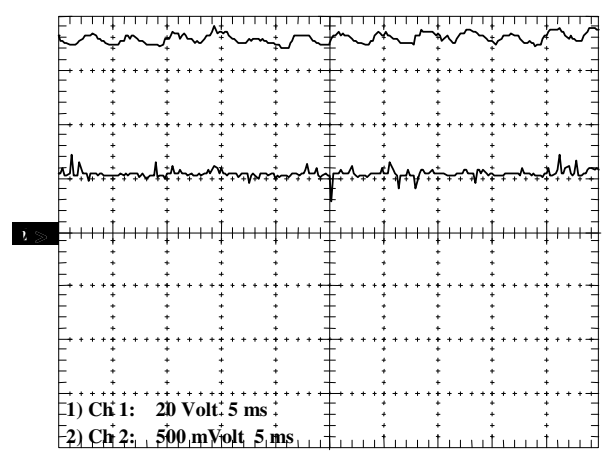

Fig. 13 - Voltage and current over the load

Tests results confirmed that using the alternative converter the system fed the load even when the SRG was not running. In this test the measurements at the input were $65 \mathrm{~V}$ and $6 \mathrm{~A}$ and thus the input power was $390 \mathrm{~W}$. Although the voltage, current and power in the load were $63 \mathrm{~V}, 6 \mathrm{~A}$ and $378 \mathrm{~W}$ respectively. Fig. 14 shows the voltage and the current delivered to the load. As the SRG was not running, the differences are only due to passing through the windings and converter without switching. So, the global losses were $12 \mathrm{~W}$ or $3 \%$.

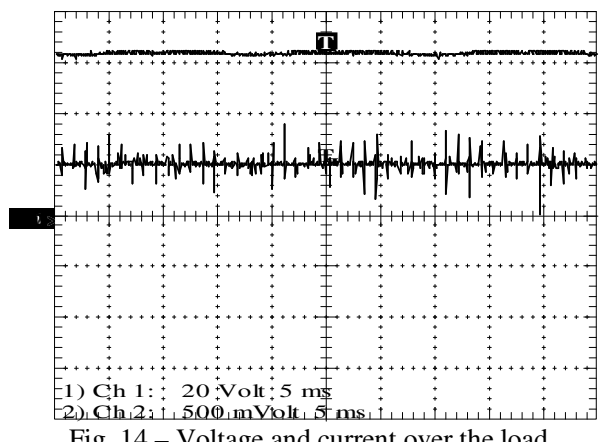

In the second test, under the same conditions, it was used a half bridge converter. The results obtained were $35 \mathrm{~V}$ and $3 \mathrm{~A}$. So the excitation power was $105 \mathrm{~W}$. The diodes and controlled switches were the same. Also the load was the same. Fig. 15 shows the current and voltage at a phase winding.

Fig. 16 shows that the output values were $50 \mathrm{~V}$ and $5 \mathrm{~A}$ resulting $250 \mathrm{~W}$. As the excitation power was $105 \mathrm{~W}$, the SRG was generating $145 \mathrm{~W}$ to the load plus all the losses. .

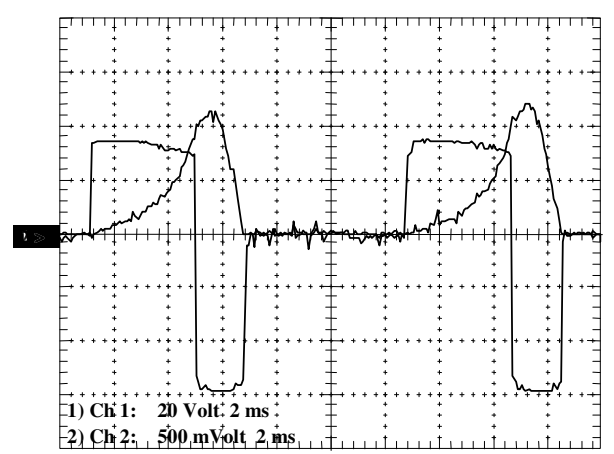

Fig. 15 - Voltage and current on the winding.

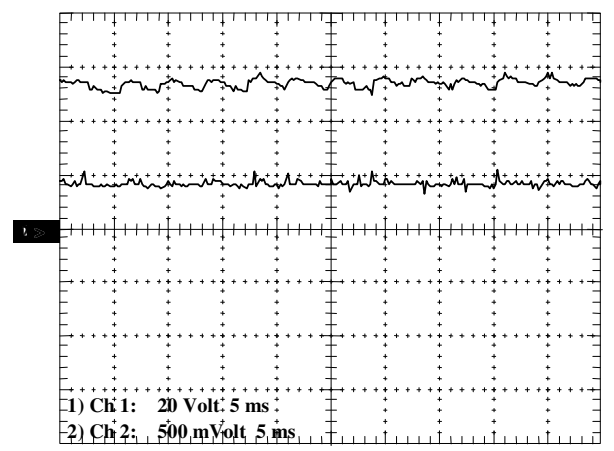

Fig. 16 - Voltage and current for the load

This result was recurrent: all the tests conducted showed that the half bridge converter has more losses, even when all parameters are confirmed to be the same, as expected. This confirmed result is due to the reduced switches count at the alternative converter

\section{CONCLUSIONS}

The SRM can operate as a generator and a prototype was simulate and tested successfully, using two different converter topologies. Although the half bridge topology is largely used, it was not the better choice for the SRG prototype tested. An alternative reduced switches count converter was more efficient when compared to the regular half-bridge one. It is also cheaper. Furthermore, the alternative converter allowed to feed the load when the SRG was not running. This is a remarkable advantage when one deals with wind power grid connected. So the SRG is an special electrical generator that emerges as an alternative available for special applications such as wind power.

\section{ACKNOWLEDGEMENTS}

The authors are grateful to the Universidade Católica de Goiás - UCG and to the Universidade Estadual de Goiás UEG for their support to this work.

\section{REFERENCES}

[1] Andrade, D. A., Costa, R. S., Teixeira, R. S., Fleury, A. (2006). Energy Efficiency for Fractional Power Loads, Industry Applications Magazine, Vol. 12, No 6, November|December 2006, pp. 12-20.

[2] Cardenas, R., Peña, R., Perez, M., Asher, G., Clare, J., Wheeler, P. (2004). Control system for grid generation of a swithed reluctance generator driven by a variable speed wind turbine, Industrial Electronic Society, 2004. IECON 2004. 30th Annual Conference of IEEE, Vol. 2 , 2-6 nov. 2004, pp. 1879-1884. 
[3] Sawata, Tadashi (2001). The switched reluctance generator, Electronic Control of Switched Reluctance Machines, Newness Power Engineering Series, Ed. T. J. E. Miller, Oxford, pp. 227-251. 